\title{
GEOLOGIA E GEOFÍSICA NA EXPLORAÇÃO DE RECURSOS MINERAIS MARINHOS
}

\section{INTRODUÇÃO}

\author{
Editores: Sidney L. M. Mello \& Jorge J. C. Palma
}

Os oceanos cobrem cerca de $71 \%$ da superfície da Terra, representando assim um ecossistema de reconhecida importância para o homem. Os oceanos dispõem de uma enorme fonte de recursos vivos e não vivos, bem como são responsáveis pelo saldo positivo de oxigênio na atmosfera através do metabolismo planctônico e pelo balanço climático resultante da distribuição e temperatura das massas d'água.

Doze das vinte maiores áreas urbanas do mundo estão localizadas dentro de um raio de 160 $\mathrm{km}$ da linha de costa, o que demonstra uma crescente relação do homem com os oceanos sob os mais diferentes aspectos, incluindo não só a pesca, o transporte, o lazer, a segurança, mas também a explotação mineral. Somente o Brasil possui cerca de $8.000 \mathrm{~km}$ de litoral, o que lhe confere uma posição estratégica privilegiada em termos da explotação sustentável dos recursos do mar.

Em termos de recursos minerais, o sal presente na água dos oceanos é por si só um bem mineral e fonte sustentável de elementos economicamente importantes, como por exemplo, $\mathrm{Cl}, \mathrm{Na}, \mathrm{Mg}, \mathrm{K}, \mathrm{Br}, \mathrm{Sr}$ e B. Entretanto, até o presente, os únicos elementos comercialmente extraídos da água do mar em grande escala são o sódio $(\mathrm{Na})$, cloro $(\mathrm{Cl}),(\mathrm{Mg})$ e bromo $(\mathrm{Br})$.

Embora a água do mar seja rica em elementos de valor econômico, a maioria dos recursos minerais encontrados nos oceanos estão relacionados a ambientes geológicos específicos, e, portanto, à interação entre a água do mar e outros agentes, tais como aporte sedimentar de rios, atividade biológica e magmatismo. Desta forma, diversos mecanismos de enriquecimento, os quais muitas vezes agem conjuntamente, levam à formação de jazidas minerais. Típicos mecanismos de enriquecimento incluem a precipitação, a sedimentação, o metabolismo biológico, a concentração diagenética e a atividade vulcânica. Portanto, os depósitos minerais marinhos são encontrados em diferentes ambientes geológicos desde as margens continentais até cordilheiras mesoceânicas.

Entretanto, a despeito das três decadas de intensa pesquisa nos oceanos, o potencial econômico dos recursos minerais marinhos ainda está abaixo daquele estimado por diversos relatórios na década de 70. Salvo o petróleo que possui importante papel na produção mundial de energia, somente alguns depósitos minerais marinhos têm sido minerados economicamente: os placers de minerais pesados, as areias e cascalhos, as conchas calcárias, os evaporitos e depósitos de fosforitas. Todavia, os depósitos minerais marinhos em geral, podem representar um importante recurso a médio e longo prazo, dependendo de conjunturas internacionais, e, portanto, merecem total atenção no que diz respeito aos estudos relacionados à sua atual exploração e explotação. A distribuição, concentração e gênese desses depósitos servem inclusive como modelo para a caracterização dos depósitos de origem marinha, atualmente encontrados no continente. Por estes motivos, os recursos minerais marinhos hoje devem ser entendidos como um recurso predominantemente estratégico.

O governo brasileiro através da Comissão Interministerial para os Recursos do Mar (CIRM) está atento a este assunto e criou, em 1997, o Programa REMPLAC para promover o efetivo conhecimento dos recursos minerais da margem 
continental brasileira. O referido programa vem desde então fomentando as atividades de trabalho, workshops e as pesquisas no setor.

Neste sentido, em agosto de 2000, foi realizado no Departamento de Geologia da Universidade Federal Fluminense um Seminário sobre Recursos Minerais Marinhos. Este seminário teve apoio do Programa REMPLAC através da Secretaria da Comissão Interministerial para os Recursos do Mar (SECIRM), Programa de Geologia e Geofísica Marinha (PGGM) e Companhia de Pesquisas e Recursos Minerais (CPRM - Serviço Geológico do Brasil). O encontro também teve apoio da Sociedade Brasileira de Geofísica (SBGf), da Fundação de Amparo à Pesquisa do Estado do Rio de Janeiro (FAPERJ) e do Departamento de Recursos Minerais do Estado do Rio de Janeiro (DRM/RJ).

Como resultado do Seminário foi elaborado um CD-ROM com uma síntese das apresentações orais (Edição limitada do Departamento de Geologia LAGEMAR/UFF). Nesta edição especial da Revista Brasileira de Geofísica apresentamos os artigos completos resultantes destas apresentações. Peter Rona abre esta edição abordando o papel dos recursos minerais na virada do século, enquanto um total de 14 artigos versam sobre os métodos e técnicas de exploração no mar, depósitos minerais e mineração submarina e ainda impactos ambientais e aspectos legais. Contribuíram com artigos Alberto Figueiredo, Abílio Gomes, Arthur Aiyres Neto, Ben Clennell, Cleverson Silva, Gilberto Dias, Isa Brehme, Ivo Pessanha, Jorge Palma, Kaiser de Souza, Luiz F. S. Braga, Marcelo Sperle Dias, Sandra Quental e Sidney Mello. Tais artigos foram submetidos à RBGf na ocasião do Seminário e, após revisão, foram aceitos para publicação em agosto/setembro de 2001. Ainda em tempo, acrescentamos a esta edição dois artigos que não constavam das apresentações do Seminário. Convidamos Bramley Murton para estabelecer um painel sobre o potencial de recursos minerais nas plataformas continentais jurídicas a partir do seu relatório para a Autoridade Internacional do Leito Marinho e Edson Milani, José Augusto Brandão, Pedro Zalán e Luiz Gamboa para abordarem a ocorrência de petróleo na margem continental brasileira. De forma direta ou indireta destacamos ainda a contribuição dos seguintes colegas: Adalberto Silva, Alexandre Tagore de Albuquerque, Carlos Schobbenhaus, Davi Santiago de Macedo, Egydio Chianello, Emmanuel T. de Queiroz, Fernando Barriga, Flávio Luiz Giacomazzi, George Satander Freire, Geraldo Cunha, Hugo Camerini, Ícaro Vitorello, José A. Baptista Neto, Jurandyr Schmidt, Marco Aurélio Latgé, Marcus Aguiar Gorini, Norberto Olmiro H. Filho, Rubens Rulli Costa, Sergio Jacques e Susanna E. Sichel.

Esta edição da RBGf apresenta-se como um meio de oportuna atualização sobre o tema recursos minerais marinhos, inclusive daqueles depósitos que ocorrem em oceano profundo (nódulos e sulfetos polimetálicos), os quais possuem enorme valor estratégico, pois ocorrem em águas internacionais e o Brasil ainda não estabeleceu suas diretrizes de pesquisa e a exploração neste campo. Esta edição também responde à ausência de publicações nacionais sobre o assunto, sobretudo com artigos majoritariamente em língua portuguesa.

Apresentamos aqui o estado da arte das pesquisas de exploração e explotação dos recursos minerais marinhos nos diferentes ambientes geológicos, caracterizando também os estudos ambientais associados às jazidas em lavra e os possíveis impactos ambientais em sítios ainda não explotados. Abordamos ainda a questão da legislação internacional associada ao uso dos recursos do mar dentro e fora da Zona Econômica Exclusiva, bem como o potencial econômico dos bens minerais nos diferentes jazimentos. 